\title{
Analysis of the hemostatic efficacy of polyurethane foam using a novel method to compare topical hemostatic agents in a rat tail-tip model
}

\author{
Ferdinand I. Broekema ${ }^{1}$, Wim Van Oeveren ${ }^{2,3}$, Rudolf R.M. Bos ${ }^{1}$
}

\author{
${ }^{1}$ Department of Oral and Maxillofacial Surgery, University Medical Center Groningen, University of Groningen, \\ Groningen, Netherlands \\ ${ }^{2}$ Department of Cardiothoracic Surgery, University Medical Center Groningen, University of Groningen, Groningen, \\ Netherlands \\ ${ }^{3}$ Haemoscan, Stavangerweg 23-23, 9723 JC Groningen, Netherlands
}

Received: 28 May 2016

Accepted: 02 July 2016

\section{*Correspondence:}

Dr. Ferdinand I. Broekema,

E-mail: f.i.broekema@umcg.nl

Copyright: () the author(s), publisher and licensee Medip Academy. This is an open-access article distributed under the terms of the Creative Commons Attribution Non-Commercial License, which permits unrestricted non-commercial use, distribution, and reproduction in any medium, provided the original work is properly cited.

\begin{abstract}
Background: A broad variety of topical hemostatic agents are used in the surgical disciplines. We analysed the most widely used topical hemostatic agents and compared them to a recently developed, synthetic topical hemostatic agent based on polyurethane (PU). The materials were compared using a novel testing method based on a rat tail-tip model. Tests were also performed with PU that was enriched with the procoagulant substance chitosan to evaluate if this could increase its hemostatic efficacy.

Methods: The following topical hemostatic agents were compared using a rat tail tip model: Collagen, gelatin, oxidized regenerated cellulose, chitosan dressing, PU and PU with chitosan. The tail tip was fixated on a developed test device to ensure a constant and equal pressure of the test material on the wound. The mean bleeding time was determined and compared between the groups.

Results: PU showed a mean bleeding time of $23.9 \mathrm{~min}$. This was not significantly shorter or longer than gelatin (23.6 $\mathrm{min})$, collagen $(28.2 \mathrm{~min}$ ) or oxidized regenerated cellulose $(26.9 \mathrm{~min})$. The addition of chitosan to PU did lead to the shortest mean bleeding time (21.5 min) but this was not significantly faster than PU without chitosan.

Conclusions: These results show that PU is a promising alternative for the most widely used topical hemostatic agents. Future studies will have to show if the addition of procoagulant substances like chitosan can significantly improve the hemostatic efficacy of PU.
\end{abstract}

Keywords: Hemostasis, Tail-tip, Collagen, Gelatin, Polyurethane

\section{INTRODUCTION}

Many different topical hemostatic agents are used in the surgical disciplines. The most widely used agents are collagen, gelatin and oxidized regenerated cellulose (ORC). There is no consensus on which of these agents has the best hemostatic efficacy and each product has significant potential drawbacks. As a result, none of the products has become dominant over the other topical hemostatic agents. ${ }^{1}$
A disadvantage of collagen and gelatin hemostatic agents is that they are animal derived and therefore carry the potential risk of pathogen transmission. The ORC can lead to inflammation of surrounding tissue and delay wound healing because of its low $\mathrm{pH}^{2}$

A recently developed fully synthetic topical hemostatic agent with a good biocompatibility could avoid these potential risks. Polyurethane (PU) is a synthetic, biodegradable material with good biocompatible properties. ${ }^{3}$ The hemostatic capacity of this material was 
increased in an in vitro study by combining it with a high percentage of polyethylene glycol (PEG). ${ }^{4}$ Coagulation is initiated by platelets that adhere to the PU surface while the PEG is believed to enhance the absorbable properties of the PU which increases the concentration of the endogenous coagulation factors and platelets. The hemostatic effect of cellulose- and polysaccharide-based hemostatic agents is partially based on this mechanism. ${ }^{5,6}$ Furthermore, PEG increases the hydrophilicity of the material and the greater volume of water within the polyurethane can allow for a greater amount of hydrolysis, and thus degradation, to take place. ${ }^{7,8}$ The PU can be formulated into membranes and foams that can be directly applied to the wound surface.

In this study, the hemostatic efficacy of a PU foam was compared to a collagen, gelatin and ORC material in a newly developed standardized rat model. This was done to analyse the hemostatic efficacy of the new material compared to the most widely used hemostatic agents.

To evaluate if this new hemostatic agent could be improved by adding a procoagulant substance, tests were also performed with PU combined with synthetic chitosan which is also known as Poly D-Glucosamine. Chitosan is the deacetylated form of chitin (poly-N-acetyl glucosamine). Both substances have a similar hemostatic action mechanism which is believed to result from mechanical sealing, vasoconstriction and the mobilization of erythrocytes, clotting factors and platelets to the site of the injury. ${ }^{9,10}$ HemCon is a chitosan dressing (CD) and was also investigated to analyse if these results would match the PU with chitosan. HemCon is a relatively new hemostatic agent that has shown a good hemostatic efficacy in humans. ${ }^{11,12}$

The materials were compared with each other using a previously described rat tail-tip model that was currently modified to acquire a new standardized test model. ${ }^{13,14}$ In this model the tail was transected at $5 \mathrm{~mm}$ from the tip and the test materials were applied to the wound with a constant and equal pressure until cessation of the bleeding occurred.

\section{METHODS}

\section{Animals}

The study was approved by the Committee for Animal Experiments at the University of Groningen, The Netherlands (Approval code: 5671B). Eighty male adult Wistar rats weighing 200 to 300 grams were obtained from Charles River, The Netherlands. The animals had unrestricted access to food and water.

\section{Materials}

Tests were performed with seven different test materials.
Hémocollagène (absorbable collagen hemostat; Septodont, Saint-Maur-des-Fossés, France) sponges $\left(1 \mathrm{~cm}^{3}\right)$ were used as collagen hemostatic agent.

Spongostan (absorbable gelatin sponge; Johnson and Johnson, Skipton, United Kingdom) sponges $\left(1 \mathrm{~cm}^{3}\right)$ were used as gelatin hemostatic agent.

Surgicel (absorbable oxidized regenerated cellulose; Ethicon, Neuchâtel, Switzerland) knitted fabric $(1.25 \mathrm{~cm} \mathrm{x}$ $5 \mathrm{~cm}$ ) was used as ORC hemostatic agent.

HemCon (chitosan-based wound dressing; HemCon Medical Technologies, Inc, Portland, Oregon, USA) was used as CD hemostatic agent.

Sterilux (sterile gauze compression bandages; Hartmann, Heidenheim, Germany) gauze pads $(5 \mathrm{~cm} \times 5 \mathrm{~cm})$ were used as control agent.

The tested PU was a block-copolymer composed of urethane hard segments and co-polyether-ester soft segments. The soft segments (total molecular weight: $2.000 \mathrm{~g} / \mathrm{ml}$ ) consisted of $50 \%$ DL-lactide and $50 \% \varepsilon-$ caprolactone. PEG 1.000 was used as initiator for the soft segments synthesis, and after that PEG 20.000 was added in a mass ratio of 3 (first PU formulation) to 1 (PEG 20.000) to prepare a blend. The urethane segments were synthesized with 1,4-butanediisocyanate (BDI) and 1,4butanediol (BDO). They had a uniform length of 5 urethane moieties, which resulted in a PU with BDIBDO-BDI-BDO-BDI urethane segments in the polymer. The PU was then dissolved in 1,4-dioxane. After dissolving, the solution was poured into a mold and cooled down to $-18^{\circ} \mathrm{C}$. The solution was freeze-dried at 3 mbar to remove the 1,4-dioxane crystals, resulting in an highly porous foam with a porosity of $97 \%$ and an overall PEG-content of $55 \mathrm{wt} \%$. Overall porosity was calculated after determining the weight and dimensions of the foams.

The PU foams with chitosan were made in the same way except for the addition of synthetic chitosan powder. After the PEG 20.000 was added, chitosan powder was added to the blend resulting in PU foams with a concentration of $50 \mathrm{mg}$ chitosan per foam.

The PU foams had a cylindrical shape with a size of 1 $\mathrm{cm}^{3}$ and were ultimately sterilized using ethylene oxide. The polymers and foams were manufactured by Polyganics BV (Groningen, The Netherlands).

\section{Test device}

A novel test device was developed for this test to ensure a constant and equal pressure of the test material on the wound (Figure 1). This test device consisted of a metal plate $(30 \mathrm{~cm} \times 15 \mathrm{~cm} \times 2 \mathrm{~cm})$ on which the tail of the rat and the test material could be fixated. The test material was placed on a sliding device on the metal plate. A 
weight of $155 \mathrm{~g}$ was attached to the sliding device via a pulley to ensure that a constant pressure would be applied to the wound. The weight created a constant pressure of $0.29 \mathrm{~N} / \mathrm{mm}^{2}$ that was applied to the wound. This was calculated out of the mass $(0.155 \mathrm{~kg})$ and acceleration of gravity $\left(9.813 \mathrm{~m} / \mathrm{s}^{2}\right)$, which gave a force of $1.521 \mathrm{~N}$ $(0.155 * 9.813)$. This force was divided through the mean bleeding area of the wound $\left(5.31 \mathrm{~mm}^{2}\right)$ which led to a pressure of $0.29 \mathrm{~N} / \mathrm{mm}^{2}\left(2.9 * 10^{5} \mathrm{~Pa}\right)$. For this calculation we assumed that the friction in the device was negligible.

\section{Study protocol}

The eighty rats were randomly assigned to one of eight test groups of 10 animals each. From the eight test groups, seven were treated with a test material and one served as a negative control group and received no treatment. The tested materials were collagen, gelatin, oxidized regenerated cellulose, a chitosan dressing, gauze, PU foam and PU foam combined with chitosan.

The animals were anesthetized by inhalation of $5 \%$ isoflurane and weighed before surgery. During the surgery anesthesia was maintained by inhalation of 2$2.5 \%$ isoflurane. The animals were placed in a prone position on a platform with their tails resting $10 \mathrm{~cm}$ below the surface on the test device. A warming mat was placed under the rat to keep the temperature of the rat at $37^{\circ} \mathrm{C}$. The rat tail was fixated on a platform on the developed test device with tape. The tail tip was placed 7 mm over the edge of the platform and transected at $5 \mathrm{~mm}$ from the tip. The mean diameter of the tail tip was 2.6 $\mathrm{mm}$ (SD: 0.24 ) and the mean weight of the transected tail-tip was $0.016 \mathrm{~g}$ (SD: 0.003).

After transection of the tail, the test material was applied to the wound during three minutes. After three minutes the test material was removed and the wound was blotted with filter paper. This was repeated every minute until no blood was observed on the paper upon blotting. The time from the tail transection to the bleeding cessation was the bleeding time. During the experiment the tested material was replaced by a fresh one every ten minutes to prevent that the materials got fully saturated with blood and consequently might loose their hemostatic effect. After completion of the experiments, the animals were euthanized by intravenous administration of $0.5 \mathrm{ml}$ of pentobarbital sodium $(200 \mathrm{mg} / \mathrm{ml})$.

\section{Statistical analysis}

Statistical analysis was performed using SPSS 20.0. The mean bleeding time of PU was compared to the other materials with the Mann-Whitney- $U$-test. Using the Bonferroni correction a $\mathrm{p}$ value less than $(0.05 / 5=) 0.01$ was considered statistically significant. For the second comparison including the PU with chitosan a $\mathrm{p}$ value less than $(0.05 / 3=) \quad 0.017$ was considered statistically significant.

The hemostatic agents collagen, gelatin, ORC and CD were compared using a Kruskal-Wallis test. A p value less than 0.05 was considered statistically significant for this test.

\section{RESULTS}

The mean bleeding time and standard deviation was calculated per material and presented in table 1 in order of efficacy.

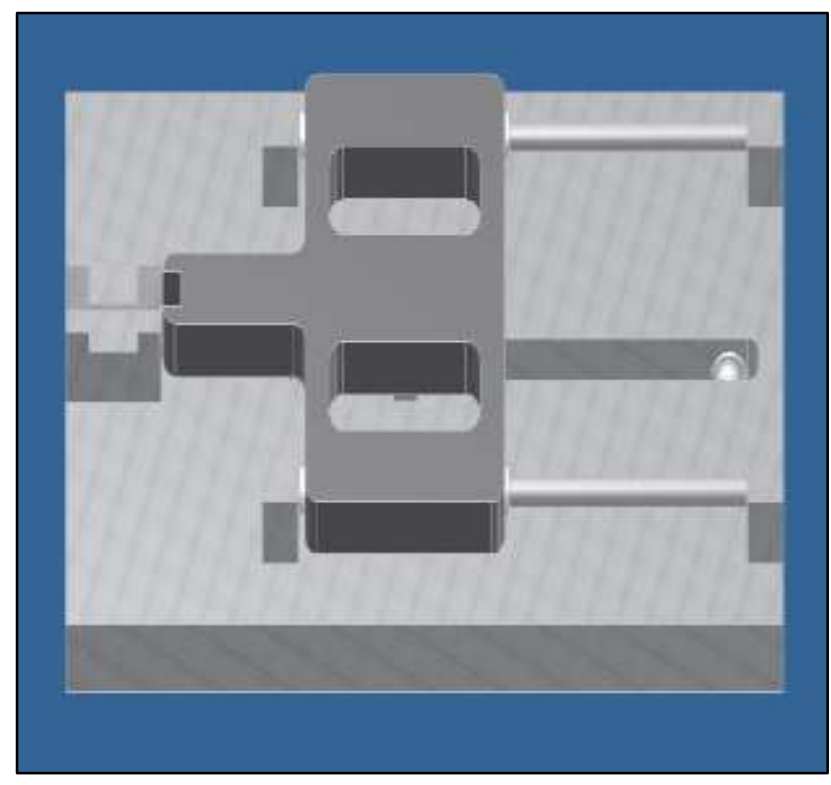

Figure 1: Schematic picture of the test device that was used to compare the different test materials. The tail was fixated on the platform on the left. The test material was placed in the sliding device in the middle. A weight that was connected to the sliding device via two pulleys ensured a constant pressure to the wound.

PU was first compared to collagen, gelatin, ORC, gauze and the control group without material. This showed that the bleeding time of PU was not significantly different from collagen $(\mathrm{p}=0.24)$, gelatin $(\mathrm{p}=0.70)$ and ORC $(\mathrm{p}=0.27)$.

The difference with gauze and the control group without material was significant with a $\mathrm{p}$ value $<0.001$ (Figure 2).

PU was also compared to the PU that was combined with chitosan to analyze if this would improve the hemostatic efficacy. Furthermore, the chitosan dressing (CD) HemCon was included in this comparison to evaluate how this material would relate to the PU with chitosan (Figure 3). 
The bleeding times of PU with and without chitosan were not significant $(\mathrm{p}=0.27)$. The difference between PU and CD was also not significant $(p=0.13)$. The PU with chitosan did have a significantly shorter bleeding time than $C D$ with a $p$ value of 0.004 . The differences between collagen, gelatin, ORC and CD were not significant $(\mathrm{p}=0.14)$.

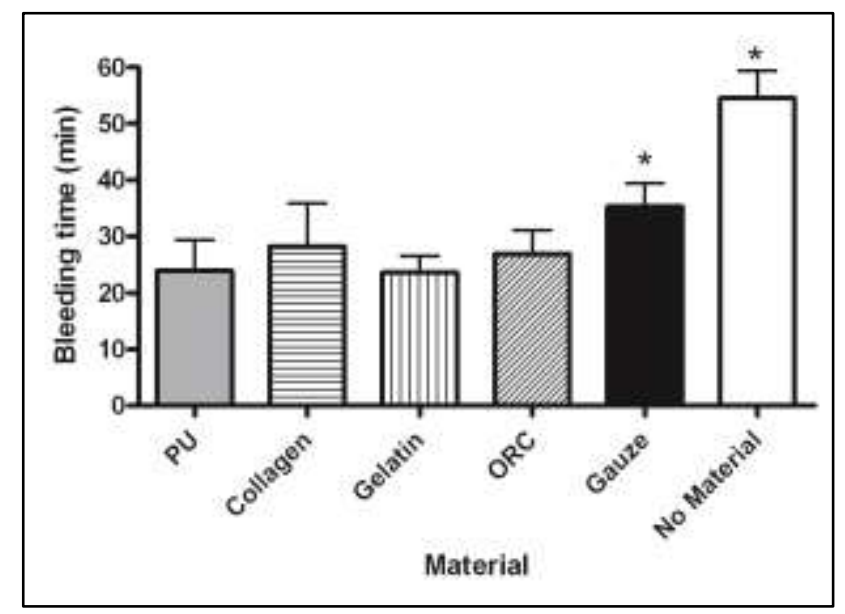

Figure 2: Schematic representation of the mean bleeding time and standard deviation for the different test materials. PU, polyurethane; ORC, oxidized regenerated cellulose. *p $<0.001$ compared with PU.

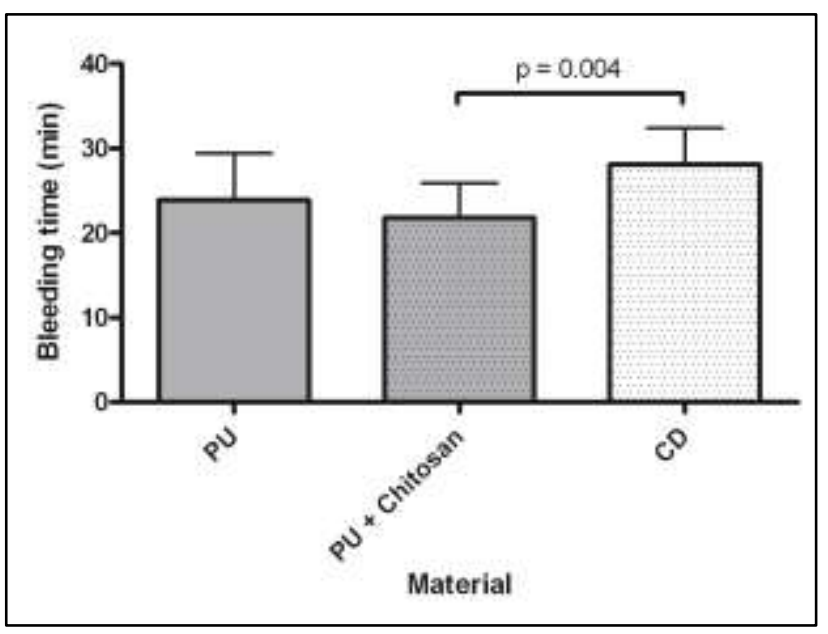

Figure 3: Schematic representation of the mean bleeding time and standard deviation for $\mathrm{PU}$ with and without chitosan and CD. PU, polyurethane; CD chitosan dressing.

\section{DISCUSSION}

In this study the hemostatic efficacy of the most widely used topical hemostatic agents was compared to a recently developed synthetic hemostatic agent based on polyurethane. This was done using a novel method based on a rat tail-tip model. The polyurethane foam was combined with chitosan to analyse if the hemostatic efficacy could be improved by adding a procoagulant substance. We found that the mean bleeding time of PU was not significantly longer or shorter than the most widely used topical hemostatic agents. The addition of chitosan to PU did lead to a shorter mean bleeding time but the difference was not significant. Thus, the addition of chitosan to the PU foam could not improve its hemostatic efficacy.

Previous studies on the hemostatic efficacy of widely used topical hemostatic agents showed various results. A number of studies concluded that the hemostatic agents had comparable results. ${ }^{15-17}$ Several studies found collagen to be the most effective topical hemostatic agent. $^{4,18,19}$ Other studies pointed out chitin as the most effective topical hemostatic agent. ${ }^{1,20}$

Table 1: Mean bleeding time and standard deviation of the tested materials in order of efficacy.

\begin{tabular}{|lll|}
\hline Material & $\begin{array}{l}\text { Mean bleeding time } \\
(\text { min) }\end{array}$ & $\begin{array}{l}\text { Standard } \\
\text { deviation }\end{array}$ \\
\hline PU + Chitosan & 21,5 & 3,75 \\
\hline Gelatin & 23,6 & 2,95 \\
\hline PU & 23,9 & 5,49 \\
\hline ORC & 26,9 & 4,20 \\
\hline CD & 28,1 & 4,28 \\
\hline Collagen & 28,2 & 7,63 \\
\hline Gauze & 35,3 & 4,11 \\
\hline No material & 54,5 & 4,86 \\
\hline
\end{tabular}

PU, polyurethane; ORC, oxidized regenerated cellulose; $\mathrm{CD}$, chitosan dressing.

Our study also showed no clear favourite amongst the tested topical hemostatic agents. The addition of chitosan to the PU foam could not improve its hemostatic efficacy. This could be caused by mixing the chitosan through the foam. As a result the chitosan concentration at the surface of the foam might not have been high enough to exert an additional effect. Future studies with a higher concentration of chitosan or a layer of chitosan at the surface will have to show if the addition of chitosan is a possibility to increase the hemostatic efficacy of PU.

The chitosan-based dressing HemCon showed a significantly longer bleeding time than the PU foam with chitosan. This might be explained by the hemostatic action mechanism of HemCon. The product becomes sticky upon contact with blood and creates an enhanced tissue adhesion. ${ }^{21}$ In the used test model, the hemostatic agent had to be removed from the wound regularly to analyse if the wound was dry. The sticky property of the chitosan could have led to partial removal of the blood clot and thus a longer bleeding time.

We used a novel testing method that was modified from other studies. ${ }^{13,14}$ The most important modification was the use of a test device that was developed for this study. The test device ensured a constant pressure to the wound that was equal for all test materials. This is a major 
improvement because compression by the researcher inevitably leads to varying pressure to the wound. The removal of the tail at $5 \mathrm{~mm}$ from the tip led to a wound diameter with a low standard deviation and thus to comparable and reproducible wounds. The use of this novel test method enabled us to compare multiple different topical hemostatic agents in a standardized manner.

This study also demonstrated a drawback of the novel test method as the hemostatic agent had to be removed every minute to check if the wound was dry. This sometimes led to a partial removal of the blood clot when the material was removed to check the wound. The effect was equal for all test materials but might have disadvantaged the chitosan which becomes sticky upon contact with blood. ${ }^{21}$

\section{CONCLUSION}

The PU foam showed a comparable mean bleeding time as the widely used hemostatic agents in this novel test model that enabled us to compare topical hemostatic agents in a standardized manner. The PU combined with chitosan showed the shortest mean bleeding time but this was not significantly different from PU. We conclude that PU is a promising alternative for the most widely used topical hemostatic agents. Future studies will have to show if the addition of procoagulant substances like chitosan can significantly improve the hemostatic efficacy of PU.

\section{ACKNOWLEDGMENTS}

The authors gratefully acknowledge R. de Graaf, J. Jankie, and B.C. Bhat for the development and production of the PU foams.

Funding: This study was financially supported by Polyganics BV and the University Medical Center Groningen, The Netherlands'

Conflict of interest: None declared

Ethical approval: The study was approved by the institutional ethics committee

\section{REFERENCES}

1. Cole DJ, Connolly RJ, Chan MW, Steven D. Schwaitzberg, Byrne TK, Adams DB. A pilot study evaluating the efficacy of a fully acetylated poly-Nacetyl glucosamine membrane formulation as a topical hemostatic agent. Surgery. 1999;126(3):5107.

2. Tomizawa Y. Clinical benefits and risk analysis of topical hemostats: A review. J Artif Organs. 2005;8(3):137-42.

3. Minnen BV, van Leeuwen MB, Kors G, Zuidema J, van Kooten TG, Bos RR. In vivo resorption of a biodegradable polyurethane foam, based on 1,4butanediisocyanate: A three-year subcutaneous implantation study. J Biomed Mater Res A. 2008;85(4):972-82.

4. Broekema FI, van Oeveren W, Zuidema J, Visscher $\mathrm{SH}, \mathrm{Bos} \mathrm{RR}$. In vitro analysis of polyurethane foam as a topical hemostatic agent. J Mater Sci Mater Med. 2011;22(4):1081-6.

5. Thatte HS, Zagarins SE, Amiji M, Khuri SF. Poly$\mathrm{N}$-acetyl glucosamine-mediated red blood cell interactions. J Trauma. 2004;57(1 Suppl):S7-12.

6. Kanko M, Liman T, Topcu S. A low-cost and simple method to stop intraoperative leakage-type bleeding: Use of the vancomycin-oxidized regenerated cellulose (ORC) sandwich. J Invest Surg. 2006;19(5):323-7.

7. Skarja GA, Woodhouse KA. In vitro degradation and erosion of degradable, segmented polyurethanes containing an amino acid-based chain extender. J Biomater Sci Polym Ed. 2001;12(8):851-73.

8. Fromstein JD, Woodhouse KA. Elastomeric biodegradable polyurethane blends for soft tissue applications. J Biomater Sci Polym Ed. 2002;13(4):391-406.

9. Achneck HE, Sileshi B, Jamiolkowski RM, Albala DM, Shapiro ML, Lawson JH. A comprehensive review of topical hemostatic agents: Efficacy and recommendations for use. Ann Surg. 2010;251(2):217-28.

10. Ikeda Y, Young LH, Vournakis JN, Lefer AM. Vascular effects of poly-N-acetylglucosamine in isolated rat aortic rings. J Surg Res. 2002;102(2):215-220.

11. Wedmore I, McManus JG, Pusateri AE, Holcomb JB. A special report on the chitosan-based hemostatic dressing: Experience in current combat operations. J Trauma. 2006;60(3):655-8.

12. Brown MA, Daya MR, Worley JA. Experience with chitosan dressings in a civilian EMS system. J Emerg Med. 2009;37(1):1-7.

13. Paez X, Hernandez L. Topical hemostatic effect of a common ornamental plant, the geraniaceae pelargonium zonale. J Clin Pharmacol. 2003;43(3):291-5.

14. White CM, Fan C, Chow M. An evaluation of the hemostatic effect of externally applied notoginseng and notoginseng total saponins. J Clin Pharmacol. 2000;40(10):1150-3.

15. Kheirabadi BS, Field-Ridley A, Pearson R, MacPhee M, Drohan W, Tuthill D. Comparative study of the efficacy of the common topical hemostatic agents with fibrin sealant in a rabbit aortic anastomosis model. J Surg Res. 2002;106(1):99-107.

16. Hong YM, Loughlin KR. The use of hemostatic agents and sealants in urology. J Urol. 2006;176(6 Pt 1):2367-74

17. Msezane LP, Katz MH, Gofrit ON, Shalhav AL, Zorn KC. Hemostatic agents and instruments in laparoscopic renal surgery. J Endourol. 2008;22(3):403-8. 
18. Wagner WR, Pachence JM, Ristich J, Johnson PC. Comparative in vitro analysis of topical hemostatic agents. J Surg Res. 1996;66(2):100-8.

19. Alexander JM, Rabinowitz JL. Microfibrillar collagen (avitene) as a hemostatic agent in experimental oral wounds. J Oral Surg. 1978;36(3):202-5.

20. Chan MW, Schwaitzberg SD, Demcheva M, Vournakis J, Finkielsztein S, Connolly RJ. Comparison of poly-N-acetyl glucosamine (PGlcNAc) with absorbable collagen (actifoam), and fibrin sealant (bolheal) for achieving hemostasis in a swine model of splenic hemorrhage. J Trauma. 2000;48(3):454-7.

21. Alam HB, Burris D, DaCorta JA, Rhee P. Hemorrhage control in the battlefield: Role of new hemostatic agents. Mil Med. 2005;170(1):63-9.

Cite this article as: Broekema FI, Oeveren WV, Bos RRM. Analysis of the hemostatic efficacy of polyurethane foam using a novel method to compare topical hemostatic agents in a rat tail-tip model. Int Surg J 2016;3:1551-6. 